$\begin{array}{ll} & \text { Etnográfica } \\ \text { etnográfica } & \text { Revista do Centro em Rede de Investigação em }\end{array}$

Antropologia

vol. 23 (1) | 2019

Vol. 23 (1)

\title{
Las ambigüedades del miedo: un análisis etnográfico sobre inseguridades en una villa de Córdoba, Argentina
}

The ambiguities of fear: ethnographic analysis about insecurities in a slum in Cordoba, Argentina

\section{Marina Liberatori}

\section{(2) OpenEdition}

\section{Journals}

Edición electrónica

URL: https://journals.openedition.org/etnografica/6255

DOI: 10.4000/etnografica.6255

ISSN: 2182-2891

\section{Editor}

Centro em Rede de Investigação em Antropologia

Edición impresa

Fecha de publicación: 1 febrero 2019

Paginación: 27-47

ISSN: 0873-6561

\section{Referencia electrónica}

Marina Liberatori, «Las ambigüedades del miedo: un análisis etnográfico sobre inseguridades en una villa de Córdoba, Argentina», Etnográfica [En línea], vol. 23 (1) | 2019, Publicado el 21 marzo 2019, consultado el 20 enero 2022. URL: http://journals.openedition.org/etnografica/6255 ; DOI: https:// doi.org/10.4000/etnografica.6255

\section{(c) (1) \&}

Etnográfica is licensed under a Creative Commons Attribution-NonCommercial 4.0 International License. 


\section{Las ambigüedades del miedo: un análisis etnográfico sobre inseguridades en una villa de Córdoba, Argentina}

\section{Marina Liberatori}

Desde hace más de una década en Argentina se ha venido gestando una profunda preocupación por la problemática social de la inseguridad. Esta categoría es a menudo relacionada con el miedo al delito desde la agenda política y algunos sectores sociales, principalmente las clases medias y altas y algunos medios de comunicación. Desde estas perspectivas se tienden a juzgar como peligrosas a personas, principalmente jóvenes hombres, que viven en villas y barrios pobres. A partir de un intenso trabajo de campo en 2009-2015, he podido observar que en villa La Tela se configuran diferentes representaciones y prácticas en relación con el miedo. Estas se vinculan con los estigmas que se construyen sobre ese lugar y sus habitantes, con las desventajas materiales de la vida en la villa, con la precariedad laboral, entre otras cuestiones. El miedo es una construcción relacional, y a veces ambigua, que presenta al menos una doble faceta entre quienes temen y quienes son temidos. Algunos jóvenes se apropian de esos estigmas de peligrosidad y maldad que les son asignados "haciéndose los malos" para conseguir diversos fines, como dinero, mujeres y respeto. Es decir, invierten el miedo usando el miedo como capital en un contexto social donde escasean otros tipos de capitales.

PALABRAS-CLAVE: miedo, inseguridad, pobreza, villa.

The ambiguities of fear: ethnographic analysis about insecurities in a slum in Cordoba, Argentina - For more than a decade a deep concern for the social problems of insecurity has been developing in Argentina. This category is often related to the fear of crime in the political agenda and among some social sectors, mainly the middle and upper classes and some media. From these perspectives, those who live in slums, and mainly young men, tend to be judged as dangerous people. Through intensive fieldwork in 2009-2015, I have been able to observe how in the La Tela slum, fear is diverse and is not sensed necessarily as related to insecurity, but to the stigmas that are built about that place and its people, the material disadvantages of life in the slum, precarious work, among other issues. Additionally, fear is a relational, and sometimes ambiguous, construction that is at least double-sided, for there are those who fear and those who are feared. Some young people appropriate those stigmas of danger and evil that are assigned to them and assume the attitude of "bad guys" for purposes such as getting money, women, and respect. In other words, they use fear as a capital in a social context where other types of capital are scarce.

KEYWORDS: fear, insecurity, poverty, slum.

LIBERATORI, Marina (marinaliberatori@gmail.com) - Conicet, UNC, Idacor, Argentina. 


\section{INTRODUCCIÓN}

¿Qué puede decirnos el miedo sobre nuestras maneras de entender y clasificar el mundo? Pensar en los miedos implica, en cierta manera, sumergirse en el mundo de las emociones, no sólo de las personas con las que trabajamos, sino también en las propias. En este sentido Halbwachs (2009 [1947]) establece que las expresiones emotivas no son de modo alguno innatas al hombre, sino que se trata de manifestaciones colectivas. El autor aclara que, aunque también existe espontaneidad personal, las emociones suelen ser comunes a todos los miembros de un grupo. Reguillo (2006) realiza un minucioso recorrido por diferentes autores que han estudiado sobre el miedo. Retoma la obra Tratado sobre las Pasiones de Hume y sugiere que el filósofo incorpora una dimensión más social en el estudio de los miedos, a diferencia de otros pensadores. Hume afirma que tanto el miedo como la esperanza nacen de una oposición de posibilidades - como el miedo a que un mal ocurra y la esperanza de que nada acontezca. Esto sugiere que la presencia de un peligro (real o imaginario) provoca de alguna manera el sentimiento de miedo. Según Hume, este último se encuentra atado a los territorios de la cultura y requiere la confirmación o negación de una comunidad de sentido. Por su parte, Da Silva Catela (2006) reflexiona sobre cómo las representaciones sobre el miedo ponen en juego nociones construidas colectivamente sobre el bien y el mal, lo justo y lo injusto. A partir de categorías sociales, como la de miedo, que entrelazan emociones y sentimientos, es posible analizar series de oposiciones, concepciones y significaciones sobre el mundo. Estas categorías remiten a un sistema de clasificaciones desde donde las personas se clasifican a sí mismas y a los demás.

En este artículo, que se enmarca en mi tesis de maestría, me propongo analizar cómo se construyen los miedos en La Tela, una de las villas ${ }^{1}$ más antiguas de la ciudad de Córdoba-Argentina, y cómo se encuentran relacionados con el "fenómeno de inseguridad", tan candente en la agenda pública nacional desde hace más de una década. A su vez, este fenómeno está, en general, asociado al delito. Como han trabajado diferentes autores, la inseguridad es pensada desde las clases más acomodadas, ciertos sectores políticos y medios de comunicación, desde donde se tiende a clasificar como peligrosas, especialmente, a las personas que viven en villas y barrios empobrecidos (Puex 2003; Isla y Míguez 2003; Míguez e Isla 2010; Kessler 2007, 2009, 2013; Liberatori 2014, 2016). Puede decirse que la vinculación entre el miedo y el delito ha sido vastamente trabajada. Los estudios pioneros sobre "miedo al crimen" o fear of crime son de origen anglosajón e indagan, en su mayoría, la racionalidad/irracionalidad, la subjetividad/objetividad entre el delito existente y las sensaciones

I Las villas o "villas miseria" son asentamientos precarios de viviendas que se ubican, generalmente, en la periferia de las ciudades. 
de inseguridad y el riesgo de victimización, especialmente, en comunidades norteamericanas y europeas (Hale 1996; Lupton y Tulloch 1999; Pain 2001). En general, sus principales preocupaciones giran en torno a la proporción entre la sensación de miedo y el peligro real existente que lo ocasiona. Desde estas perspectivas se considera que las impresiones de las personas frente a los delitos y el impacto que genera en éstas son susceptibles de ser medibles, objetivables y cuantificables, a partir, por ejemplo, de las encuestas de victimización. Sin embargo, aquí intentaré ampliar el espectro de los miedos y mostrar que en villa La Tela no siempre tienen una connotación negativa, ni se encuentran relacionados únicamente con la inseguridad. En ocasiones, el miedo tiene al menos una doble faceta entre quienes temen y quienes son temidos. Veremos cómo algunos jóvenes invierten el miedo, en sus propias palabras se "hacen los malos" volviéndose peligrosos para otros. Usar la maldad como capital se convierte en una estrategia seductora, frente a la escasez de otros capitales, para invertir la situación desventajosa que supone, desde sus propias perspectivas, la vida en la villa (Bourgois 2010).

\section{SOBRE EL TRABAJO DE CAMPO}

Llegué por primera vez a la villa en 25 de marzo de 2009; iba acompañada por Carla, una estudiante de geografía que estaba realizando un proyecto social allí. ${ }^{2}$ Ella me presentó a Zuny, una mujer de unos 45 años, "referente" de la villa que, a modo de red, me fue presentando a otros vecinos. ${ }^{3}$ El trabajo de campo que dio sustento a mi tesis de maestría y a mi tesis de doctorado en Antropología consistió en dos etapas: la primera se extendió entre marzo de 2009 y diciembre de 2013 y la segunda entre marzo y noviembre de 2015. Principalmente trabajé observando y participando de diferentes eventos locales, tales como fiestas del día del niño, bingos, peñas y meriendas comunitarias. Luego, a medida que fui estableciendo relaciones más cercanas con algunos vecinos, fui acompañándolos en sus vidas cotidianas, visitándolos a diario y en acontecimientos familiares, por ejemplo, en fiestas de cumpleaños, bautismos y velorios. La "reflexividad" fue una práctica presente durante toda la investigación. Así, no sólo fui analizando los diferentes lugares y roles que las personas me iban asignando; sino también mis propias experiencias

2 La Tela es una villa que cuenta con la presencia cotidiana de profesionales de la municipalidad y la provincia de Córdoba, tales como médicos, trabajadores sociales, psicólogos y enfermeras que desempeñan tareas en el Centro Integrador Comunitario (CIC) de La Tela. También concurren asiduamente miembros de ONGs quienes desarrollan actividades como copas de leche, apoyo escolar, huertas comunitarias, ciclos de cine, entre otras cosas. Además, asisten personas provenientes de las iglesias católica y evangélica.

3 La categoría de "referente" es usada para referir a las personas que tienen una posición social de poder debido a la antigüedad de residencia en la villa y a los contactos políticos que pueden movilizar. 


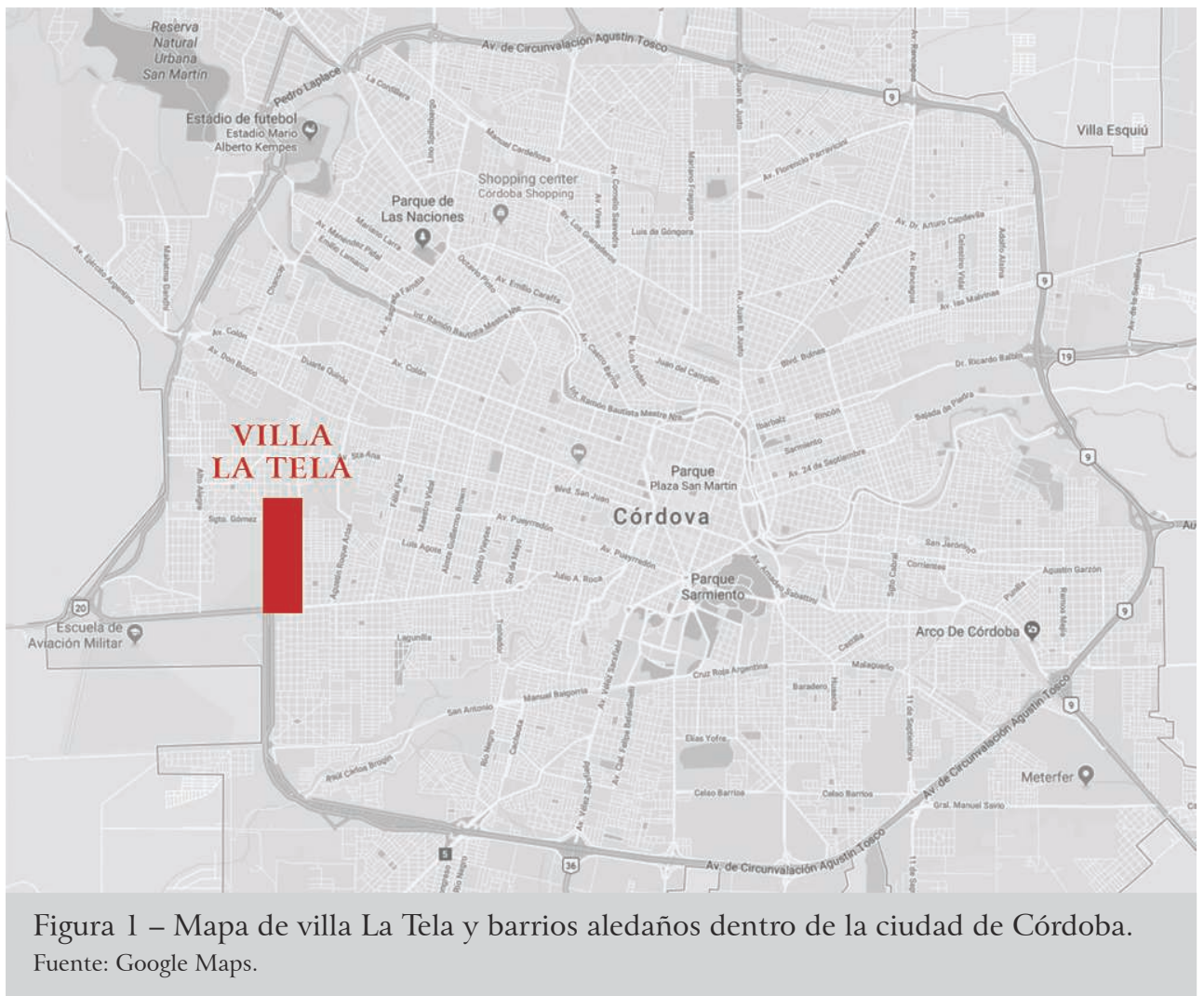

y las relaciones sociales que fui estableciendo con las personas durante el trabajo de campo, sin las cuales no hubiera podido conocer ni comprender nada muy profundamente sobre sus vidas. En este sentido, Guber afirma que "no es posible el conocimiento social desde la absoluta des-implicación; sostener la exterioridad del investigador sería creer que el sentido proviene de las cosas mismas y no de las situaciones sociales en que esas 'cosas' son dichas, invocadas y puestas en escena por actores concretos" (Guber 2014: 23). Podría decirse entonces que, tanto para la tesis de maestría como para la de doctorado, el trabajo de campo se centró en las relaciones, situaciones y redes sociales de las que fui formando parte, por lo que careció de "instancias formales". Me refiero a situaciones de entrevista pautadas como tales y mediadas por el uso de grabador. Todas las personas sabían que yo estaba realizando un "trabajo sobre la villa" y siempre, salvo excepciones, se mostraron muy entusiasmadas para colaborar conmigo. Las personas me esperaban en sus viviendas con "mate", dispuestas a conversar, luego yo anotaba las categorías e ideas principales y generalmente en el siguiente encuentro preguntaba cosas puntuales y corroboraba haber comprendido bien las ideas y 
sentidos de los relatos. ${ }^{4}$ Cabe aclarar que esto me fue posible por la duración del trabajo de campo, la cual me permitió ir conociendo más de cerca a las personas e incorporar sus categorías, formas de expresarse y de clasificar el mundo. Por el tipo de relaciones que establecí con la gente y los contextos de campo (reuniones familiares, almuerzos, fiestas y eventos barriales, reuniones casuales), el uso del grabador, lejos de contribuir con mi trabajo, lo entorpecía, puesto que quitaba "naturalidad" a los encuentros e intimidaba a las personas, sobre todo aquellas que llevaban a cabo algún tipo de actividad ilegal. En ocasiones y con determinadas personas regresaba con los escritos de las entrevistas realizadas o con alguna publicación para revisarlas juntos y a menudo ellas se sorprendían de que me acordara "de tal o cual relato, de tal o cual expresión".

Asimismo, desde el inicio del trabajo de campo fui advertida acerca de los "peligros" de circular por la villa: "acá es muy peligroso, te pueden robar porque no te conocen todavía” [Naty, 25 años, vecina de La Tela, marzo de 2009]. Así, el peligro a veces servía como mecanismo de control para delimitar qué lugares eran seguros y cuáles no para transitar la villa si uno era foráneo. Incluso me acompañaban a esperar el ómnibus dándome indicaciones: "de noche lo tenés que esperar en [tal o cual lugar] porque aunque no sea la parada hay más luz. Vos apenas lo veas aparecer [al ómnibus] te cruzas de vereda y nunca saques el celular acá, te lo pueden robar" [Carmela, 47 años, vecina de La Tela, abril de 2009]. Este tipo de advertencias me hicieron preguntarme: ¿Qué sentidos diferentes tenía el peligro en villa La Tela? ¿Qué relación tenían esas palabras con el "fenómeno de inseguridad" tan candente en la agenda pública y en los medios masivos de comunicación a nivel local y nacional? Como pude observar a través de los años, en general, en villa La Tela se espera que aquel que viene "de afuera" lo haga por un corto periodo de tiempo y luego no regrese. ${ }^{5}$ Por tanto, el trabajo de campo prolongado, entre otras variables, me ayudó a tejer lazos de confianza con algunos vecinos. Estos lazos me otorgaron la posibilidad de recorrer territorios que antes, al ser una extraña, me eran vedados. Podría decirse que, a medida que fui relacionándome con los vecinos, el miedo dejó de ser un límite que marcaba qué lugares eran peligrosos para mí y cuáles no.

4 Mate es la infusión a base de yerba mate (Ilex paraguariensis) que se bebe en algunos países de Suramérica tales como Brasil, Uruguay, Paraguay y Argentina. Se sirve en un utensilio de madera, vidrio forrado en cuero o plástico, entre otros. Se usa una bombilla (sorbete) para beber el contenido. Los usos y costumbres de esta bebida varían según el país. En Argentina, se bebe la totalidad del líquido y se devuelve el utensilio al encargado de "cebar", es decir de servir la bebida, quien vuelve a llenarlo de agua y se lo pasa a la persona que sigue (en general se empieza a cebar por la izquierda y se respeta el turno; el que ceba siempre bebe el primer mate, que es más concentrado). Es muy usual compartir esta infusión para iniciar y mantener conversaciones.

5 Los "de afuera" refiere a las personas que no viven en la villa pero que acuden cotidianamente para desarrollar algunas de las tareas que ya fueron mencionadas anteriormente. 


\section{DE VILLAS E “INSEGURIDADES” SOCIALES}

La Tela se encuentra ubicada hacia el sudoeste de la ciudad y es una de las villas con mayor extensión geográfica. Se ha venido conformando desde los años 70, década en la que comenzó, en América Latina, un proceso de modernización y reorganización, tanto de las estructuras económicas como de las relaciones sociales y la vida cotidiana (Lechner 1998). Por estos años, en Argentina se desencadenaron procesos de exclusión vinculados, principalmente, con transformaciones producidas en el mercado de trabajo. Estos cambios en el sector laboral se relacionaban con empleos poco estables, desempleo y la consecuente exclusión de vastos grupos sociales del mercado de consumo (Isla y Míguez 2003; Míguez e Isla 2010). A su vez, La Tela registró un importante crecimiento poblacional debido a la llegada masiva de habitantes expulsados de barrios aledaños y de otros asentamientos cercanos, durante la crisis que azotó a Argentina hacia fines de la década del 90. Comparte ciertas características con otras villas del país, tales como la ilegalidad de los terrenos ocupados, la precariedad de las condiciones habitacionales y la falta de servicios públicos, como energía eléctrica, agua potable y desagües cloacales. Sin embargo, desde 2016 se viene desarrollando un proyecto de "urbanización" a partir del cual La Tela pasará de ser una villa a ser un barrio con los servicios y mejoras que eso implica.

Existen investigaciones que han analizado los diferentes procesos históricos, políticos, sociales y económicos que dieron origen a las villas en Argentina. Svampa (2010) propone que la nación argentina se ha constituido sobre la base de la oposición sarmientina de civilización/barbarie que se ha venido manifestando a lo largo de diferentes periodos históricos y en los cuales diversas personas han sido asociadas con uno u otro calificativo. ${ }^{6}$ Así, para la autora, este proceso de clasificación de los sujetos involucró prejuicios raciales y sociales cargados de la oposición entre las categorías de civilización y barbarie. Actualmente, para Svampa, la imagen de peligrosidad, asociada con lo bárbaro y con el desorden social, se encuentra representada por las poblaciones pobres y movilizadas. Por otra parte, Ratier (1971) trabajó sobre cómo los "villeros" tienen su origen político y social en "los cabecitas negras". Estos últimos han ido adquiriendo diferentes identidades relacionadas con lo mestizo, lo indígena, lo atrasado, en oposición a la conquista europea, lo blanco y la modernidad. Por ejemplo, "cabecitas negras" se llamaba a los migrantes internos que

6 La autora se refiere a Domingo Faustino Sarmiento, quien fue prócer y presidente argentino preocupado por la educación, civilización y el progreso del país. Estuvo también relacionado con las grandes masacres de los pueblos originarios en siglo XIX. La autora analiza, por ejemplo, cómo en lo que llama "Primer Centenario" eran considerados bárbaros los “sujetos nativos indígenas"; luego fueron también los inmigrantes. El peronismo en sus diferentes etapas trajo aparejados prejuicios de clase entre las masas de trabajadores que migraban del campo a la ciudad y las elites citadinas (Svampa 2010). 
abandonaban el campo para dirigirse a las ciudades en busca de mejoras laborales y modernizar sus condiciones de vida durante el siglo XX. Ratier explica que, aunque las clases dominantes citadinas se sentían amenazadas por el avance del "cabecita negra", éstos últimos se encontraban representados por las gestiones y políticas redistributivas del peronismo. Sin embargo, la caída del segundo gobierno de Juan Domingo Perón, en 1955, hizo que el "cabecita negra" retrocediera, dando paso a la imagen del "villero", quién, a diferencia de los anteriores, veía limitado su margen de acción política, económica y sus derechos sociales. ${ }^{7}$ Por tanto, la villa pasó de ser un lugar transitorio a la única posibilidad de vivienda a la que estas personas podían acceder. Es interesante cómo para Ratier la discriminación, los prejuicios y el racismo sirvieron políticamente para controlar y hacer que los "cabecitas negras" se replegaran. Estos procesos están estrechamente ligados a las imágenes sociales que actualmente se construyen sobre los sujetos que viven en villas y que están relacionadas con la inmoralidad, suciedad, vagancia, amontonamiento, analfabetismo, entre otras características negativas (Guber 2004 [1984]). Estas tienen que ver con las condiciones precarias de las viviendas, pero también con la sospecha de una moralidad dudosa de sus habitantes. Por su parte, Puex (2003) establece que las "villas miseria" han sido señaladas como portadoras del mayor foco de violencia urbana en los últimos tiempos. Esta autora llama territorialización al proceso por medio del cual se estigmatiza a un determinado lugar dentro del espacio urbano y se activan prácticas discriminatorias hacia sus habitantes.

En la ciudad de Córdoba existen ciertas políticas que consisten en recrudecer las medidas de seguridad a partir de la implementación de acciones que tienden a perjudicar a los habitantes de villas y barrios pobres. ${ }^{8}$ Esto tiene una estrecha relación con la aplicación del "código de faltas", devenido luego en "código de convivencia" por parte de la policía provincial. El mismo legitima el accionar policial para calificar a un sujeto como presunto delincuente sin la mediación de un juez. De esta manera, la policía puede señalar a una persona como sospechosa y tomar medidas preventivas valiéndose de sus rasgos físicos como el color de la piel, el barrio del que proviene, la manera de hablar o la ropa que usa. La policía se convierte entonces en un sujeto clasificador, principalmente de los jóvenes varones que se convierten en sujetos clasificados (Vianna 2007). La autora, aunque en el caso de Brasil, analiza cómo la policía es el agente al que se le atribuye la capacidad de control y organización del espacio urbano, por lo que está legitimado para reconocer a las personas "potencialmente peligrosas" para la sociedad y accionar sobre ellas. Las

7 Juan Domingo Perón fue un militar y presidente democrático argentino durante tres períodos: 1946-1952, 1952-1955 y 1973-1974. Entre otras cosas, se destacó por sus políticas redistributivas y apuntadas hacia el sector obrero.

8 Para un tratamiento más profundo y amplio sobre este tema, ver Hathazy (2014). 
políticas provinciales cordobesas enmarcadas en los discursos de "tolerancia cero" y "mano dura" apuntan a preservar, especialmente, la seguridad de las clases dominantes. Desde estos discursos, la seguridad está siempre asociada a la protección de la propiedad privada, en contra de la delincuencia, y esta última vinculada a los sectores pobres de la ciudad, especialmente a los jóvenes varones, lo que conlleva a una criminalización de la pobreza.

\section{TRABAJOS INFORMALES Y “CHANGAS DELICTIVAS”: LA INSEGURIDAD} DE LA PRECARIEDAD LABORAL

La mayoría de las personas que habita en La Tela tiene empleos informales y también recibe algún tipo de plan social. ${ }^{9}$ En general, los hombres con los que he conversado trabajan en el sector de la construcción, como guardias de seguridad en fábricas o juntando cartones, alimentos y papel en sus carros, mientras que las mujeres lo hacen en casas de familia como empleadas domésticas. ${ }^{10}$ También es bastante común que la gente improvise en sus viviendas algún negocio de venta de artículos y comestibles, como despensas, quioscos y pollerías. En este sentido, como he podido observar, existen ocasiones en las cuales la inseguridad se encuentra relacionada con las precarias condiciones laborales. De esta manera, puede decirse que el trabajo informal se caracteriza por ser inconstante, además de no cumplimentar con los derechos regulados por la legislación laboral, por lo que los salarios son bajos y el pago irregular (González de la Rocha 2006). Para González de la Rocha, el mercado está saturado de este tipo de empleos; así, plantea que se va conformando una especie de círculo vicioso de desventajas entre este tipo de trabajadores. Este círculo va determinando las posibilidades de inserción laboral de las generaciones precedentes, quienes muchas veces tienen que abandonar los estudios escolares para realizar alguna "changa" para colaborar económicamente en sus hogares. ${ }^{11}$

9 Los planes sociales refieren a diferentes tipos de subsidios y planes de empleo que el gobierno nacional, provincial o municipal otorga a personas que se encuentran desocupadas o subempleadas. La mayoría de estos planes exigen como contraprestación la realización de tareas en proyectos comunitarios, productivos y también educativos - por ejemplo, trabajos en comedores, bibliotecas populares, realización de cursos en alguna institución educativa. Dicha contraprestación laboral es aproximadamente de cuatro horas la jornada. Estos tipos de planes fueron progresivamente reemplazados por otros subsidios. Primero los "programa familia" y actualmente la "asignación universal por hijo". Para más información, consultar < www.trabajo.govar > (última consulta en diciembre de 2018).

10 Los carros son vehículos hechos de madera y tirados por caballos.

11 La categoría nativa "changa" refiere a trabajos informales. Los vecinos de La Tela realizan variados tipos de "changas", por ejemplo, limpiar vidrios de autos en la zona céntrica de la ciudad, juntar cartón, papel, vidrios y alimentos en carros tirados por caballos, entre otras. Están también las llamadas "changas delictivas", que consisten en actividades ilegales tales como robar o vender droga. 
Según datos recabados por la EPH (Encuesta Permanente de Hogares) del INDEC (Instituto Nacional de Estadísticas y Censos de la República Argentina), en Córdoba entre los años 2010 y 2014 había 95.874 personas desocupadas, de las cuales 47.205, es decir el 49,2\%, eran jóvenes de entre 18 y 29 años. A su vez, la EPH indicaba también que por esos años el rango de varones de entre 16 y 20 años se encontraba en las magnitudes más altas de desempleo. Es decir que el problema de la desocupación afectaba principalmente a jóvenes varones. Si además cruzamos esos datos con lo que venía explicando más arriba respecto de la deserción escolar, vemos que, de la población desocupada, el 45,9\% no poseía los estudios medios completos, lo que en Argentina se denomina la escuela secundaria. En otras palabras, las tasas de desempleo por nivel educativo mostraban valores altos entre desempleados con menor nivel educativo. Estos datos del INDEC contribuyen para comprender con mayor profundidad el universo de los jóvenes de villa La Tela. ${ }^{12}$

Una mañana de noviembre del año 2011, nos encontramos con Marcio y Alex, dos jóvenes de 21 y 26 años con los que ya teníamos una relación de mutua confianza establecida desde hacía un año aproximadamente. El día anterior habíamos coordinado para juntarnos en el centro de la ciudad, iba a acompañarlos a hacer unos trámites y después nos iríamos a limpiar los vidrios de los autos que pasaban por una intersección de dos calles muy transitadas: Avenida Colón y Avellaneda. Caminamos los tres juntos conversando de temas variados. Había un policía por esquina, aproximadamente, que nos observaban cuando transitábamos. Pasamos por la puerta de una escuela, les conté a los chicos que yo había ido a ese colegio.

"Alex: Uh brillaste, es re bacán este colegio. Si yo hubiera venido a este colegio hubiera terminado cuarto, quinto, sexto año, todos los años.

Marina: ¿Y a qué escuela fueron ustedes?

Alex: a un ENET cerca de la villa, pero no terminamos. ${ }^{13}$

Marina: ¿Hasta qué año hicieron?

Alex: Yo hasta tercer año [del secundario].

Marcio: Yo hice dos veces primero y dejé".

Me explicaron que antes de limpiar irían a una playa de estacionamiento para cambiarse de ropa y allá fuimos. Los chicos saludaron al que estaba a cargo de la playa como si fuera alguien habitual. Además, buscaron baldes y otros implementos de limpieza. Se cambiaron la bermuda y se pusieron una maya de baño, también trocaron las zapatillas por sandalias de goma, pero se dejaron la

12 Los datos citados se encuentran en < https://www.indec.gob.ar > (última consulta en diciembre de 2018).

13 ENET son escuelas técnicas creadas durante las presidencias de Juan Domingo Perón. 
misma remera que traían. Luego nos fuimos. Al llegar a la intersección céntrica de las calles Colón y Avellaneda, Alex se enojó muchísimo porque había varios chicos "ocupando su lugar": "Los voy a correr al vuelo a estos culiados, ya cuatro por esquina es demasiado" [Alex]. ${ }^{14}$ Se dirigió con una actitud vehemente hacia uno de los jóvenes pero justo cambió el semáforo y Marcio lo sujetó del brazo para que no armara revuelo. Había un policía parado en la esquina que nos empezó a mirar insistentemente. Alex comentó: "estoy envenenado, los voy a correr al vuelo porque en esa esquina laburo yo". ${ }^{15}$

Después Alex se dirigió hacia un poste de luz donde había colgada una mochila que pertenecía, seguramente, a los otros jóvenes; con una actitud firme la tiró al piso y en ese lugar puso la suya. Vino el dueño de la mochila tirada, la levantó del piso y Marcio más diplomáticamente les dijo que "esta esquina era de Alex". Se cruzaron los otros chicos que estaban en la vereda del frente y decidieron irse. Marcio les dijo a dos de ellos que podían volver a la tarde si querían, yo alcancé a preguntarle a uno de ellos de dónde era y me respondió de San Roque, se fueron y sólo quedó uno en la vereda del frente, sobre plaza Colón. ${ }^{16}$ Arreglaron el asunto de los baldes, al parecer los otros estaban usando un tarro de pintura que era de Alex, a cambio le dejaron un balde que según uno de los chicos le habían regalado los del restaurante Mc Donald's que está ubicado, justamente, en la esquina de Avellaneda y Colón.

Marcio y Alex comenzaron a trabajar. Pude observar que antes de que el semáforo detuviera el tránsito, ellos se repartían los automóviles para ir a limpiar. Decían las marcas en voz alta, por ejemplo, Corsa, Peugeot, y al ponerse en rojo se abalanzaban hacia el auto escogido. Al cambiar el semáforo a verde, dando paso a los autos, Alex iba con sus monedas, obtenidas de la limpieza, y las colocaba en un tacho plástico de papas fritas. Marcio después de un rato me trajo las que él había juntado y me encomendó la tarea de administrarlas. Mientras tanto yo estaba sentada en un tarro de pintura que Alex había acondicionado para que estuviera a la sombra, puesto que hacía muchísimo calor y según su opinión me haría mal el sol. Alex: "A mí no me gusta hacer esto, pero de algún lado tengo que sacar plata y si no laburo, salgo a chorear y yo me quiero rescatar". ${ }^{17}$ Alex, como otros jóvenes de La Tela, comenzó a robar desde muy temprana edad y alternó su infancia y adolescencia entre trabajos informales y "changas delictivas". Como me ha relatado su madre, con quien tengo una estrecha relación de confianza, se pasó muchos años institucionalizado en los llamados institutos de menores. Estos son lugares donde, habitualmente,

14 "Correr al vuelo": echar a una persona de un lugar con malos modales; "culiados": insulto característico de la Ciudad de Córdoba.

15 "Laburo": trabajo.

16 San Roque es un barrio aledaño a villa La Tela.

17 "Chorear": robar. 
son internados los jóvenes menores de 18 años a quienes el Estado provincial considera en "conflicto con la ley penal". Ese día se pusieron en escena sentidos que muchos de los jóvenes de La Tela construyen en relación con el estudio y el trabajo. Así, el haber asistido a una escuela cercana al centro y lejana a la villa despertaba ciertos imaginarios sobre que las primeras son mejores respecto de su calidad académica y de las personas que concurren a ellas. Un día, charlando con Naty, una mujer de unos 25 años, también vecina de La Tela, me explicaba que sus futuros hijos irían "a una escuela del centro porque quería alejarlos del ambiente de la villa”. En ese sentido, he observado que muchos padres prefieren enviar a sus hijos a escuelas céntricas y privadas y no a las que se encuentran en zonas cercanas a la villa.

Por otra parte, según Alex, él hubiera finalizado sus estudios si hubiese tenido la oportunidad de ir a una escuela ubicada en el centro de la ciudad. La mayoría de los jóvenes de villa La Tela con los que he conversado, no terminaron la escuela secundaria. Sin embargo, avanzaron más que sus padres en el ciclo escolar, puesto que en general estos últimos no alcanzaron a completar el primario. Alex aseguraba que no le agradaba el oficio de limpiavidrios, aunque prefería hacerlo como forma de obtener dinero en vez de salir a "chorear" porque él "quería rescatarse", es decir, dejar de robar. En este sentido, se puede decir que limpiar vidrios ofrece ciertos riesgos físicos que están relacionados, por un lado, con posibles enfrentamientos con otros jóvenes que "invaden" la zona de trabajo y, por el otro, con el peligro de ser detenidos por la policía por causa de infringir algún artículo del mencionado ya "código de convivencia".

Alex corrió hasta un auto y volvió cabizbajo con $\$ 0,05$ centavos en la mano. Marina: “¿Cinco centavos te dieron?”, Alex: "Sí, son muy culiados algunos”. De vez en cuando se enojaba porque le hacían señas que no les limpiara y volvía sin una moneda, Marcio parecía tener más suerte. Al rato decidimos irnos, pero antes frenamos en la puerta de un supermercado situado en la calle Colón. Alex (con expresión de deseo): “iAcá voy a trabajar yo algún día!” Marina: “¿En serio? iQué bueno!” Alex: "Sí, tengo un amigo que ahora parece que no está [hace un gesto como mirando para adentro] que me va a hacer entrar, iya dejé el currículum y todo! Sabes que si yo entro a laburar acá brillé. Yo te digo si yo tuviera un trabajo como este no choreo nunca más". Luego los chicos entraron al supermercado y cambiaron todas las monedas recaudadas por billetes. Marcio tenía \$30 y Alex $\$ 25$; salieron y nos fuimos los tres caminando por Avellaneda hasta la calle 27 de Abril, dónde tomaríamos el colectivo C2 rumbo a la villa.

Si bien los trabajos informales suponen riesgos físicos y estos son a veces percibidos negativamente en los relatos de los jóvenes, también pueden alimentar sus estrategias seductoras. Esto es presentarse como alguien rudo, peligroso y capaz de imponer autoridad y "respeto" frente a los pares. Tal es el caso de Alex cuando demostraba quién podía definir la pertenencia de una esquina 
para trabajar. Además, este tipo de actividades laborales son escogidas por algunas personas, principalmente jóvenes varones, porque no dependen de un jefe para realizarlas. De esta manera, no tienen que dar explicaciones de horarios, ni dejar comisiones de lo recaudado. Muchos jóvenes señalan de "giles" a sus pares que trabajan en relación de dependencia, sobre todo en trabajos poco calificados como el sector de la construcción. ${ }^{18}$ Los jóvenes de La Tela, en general, no han finalizado los estudios escolares, tampoco han recibido capacitación de algún oficio y si lo hicieron no fue de manera constante, por tanto no reúnen los capitales necesarios para obtener un empleo que requiere mayor calificación como, por ejemplo, el de cajero de super. Respecto de las changas como la de limpiavidrios, involucran algunas desventajas como, por ejemplo, el perjuicio de no poder recaudar la suficiente cantidad de dinero porque muchas veces los clientes no desean el servicio. Otras veces el trabajo es pagado con muy escaso dinero, lo que es leído por los chicos como una burla, una ofensa. Por el contrario, otro tipo de trabajos como el de cajero en algún comercio ofrece más estabilidad económica, como así también otro tipo de trato por parte de las personas, al menos en el imaginario de Alex. Así, como él expresaba, si tuviera un trabajo como ese, no volvería a reincidir en el "choreo". En ocasiones las "changas delictivas" pueden convertirse en una alternativa respecto de las desventajas que ofrece el mercado laboral informal. Entre éstas, según los jóvenes con los que he conversado, se encuentran los malos tratos, los riesgos laborales, las malas condiciones y la poca calificación de ciertos trabajos en comparación de otros. En este sentido, se vuelve difícil para los jóvenes de la villa obtener los empleos que desean, principalmente por la alta calificación que éstos requieren. Más aún, como dijimos, si tenemos en cuenta que la mayoría de los chicos abandona los estudios a muy temprana edad.

La precariedad laboral posee un doble sentido de peligrosidad. Por un lado, como vimos, ofrece claras desventajas respecto de los trabajos a los que pueden acceder personas de otras clases sociales, quienes manejan capitales que son requeridos para llevar a cabo estos empleos (Bourgois 2010). Sin embargo, al mismo tiempo, contribuye a la construcción y performativización de masculinidades asociadas con la rudeza debido, entre otras cosas, a la elevada exposición física que caracteriza a este tipo de trabajos. La masculinidad está vinculada, para estos jóvenes, con el "respeto", que es un capital muy valorado en la villa; disputarlo, conseguirlo y mantenerlo requiere poseer ciertos "saberes de lucha" y se demuestra "poniendo el cuerpo" (Garriga Zucal 2007). Por tanto, los trabajos formales, de baja calificación, donde se tiene relación de dependencia, son leídos, muchas veces, como una amenaza al "respeto", principalmente porque sienten que son "verdugueados" por los patrones, es 
decir humillados con malos tratos y con falta de condiciones laborales dignas. En relación con esto, una tarde de julio de 2009 conversaba con Mariano, un joven de unos 23 años vecino de La Tela y él me decía:

"Mariano: Yo soy pocero como mi papá. Es un trabajo muy peligroso ese. Marina: ¿Ah sí? ¿Por qué?

Mariano: Porque cavamos mucho bajo tierra y podemos morir asfixiados si hacemos un mal movimiento y la tierra nos empieza a tapar, te podes quedar adentro. Yo lo único que pido es un seguro de vida porque si me pasa algo mi familia puede cobrar, pero la verdad es que los patrones nos tratan como si fuéramos bolivianos.

Marina: ¿Cómo sería eso?

Mariano: Y nos pagan muy poco, a ellos no les importamos porque para ellos somos sólo peones. Los patrones sólo quieren ganar plata y por eso no les importa invertir en seguridad para nosotros" [Mariano, junio de 2009].

En general, los oficios suelen ser transmitidos de padres a hijos, pero también hay quienes no quieren seguir los pasos de sus antecesores. En este fragmento de entrevista puede observarse cómo este tipo de trabajos hace sentir denigrados a los jóvenes como Mariano, porque no son tratados como personas que "merecen respeto". Las palabras de Mariano expresan esto al compararse con un inmigrante boliviano. Más allá del dejo estigmatizante de la expresión, me interesa señalar la autopercepción del peligro al que se ve expuesto en su labor de pocero, a lo que se acrecienta el sentimiento de menosprecio percibido por parte de sus patrones.

Por otra parte, como vimos en el caso de Alex, algunos jóvenes de la villa alternan entre una economía informal, pero legal, y una economía clandestina o, en palabras de las personas con las que trabajé, "changas delictivas". Bourgois (2010) reflexiona en torno a la degradación que suponen los trabajos informales y poco calificados que realizan sus entrevistados en Harlem, en contraposición a todos los beneficios que obtienen a partir de economías clandestinas, tales como prestigio, dinero, respeto, status, mujeres, etc. Así se pregunta por qué las personas deberían conformarse con empleos poco calificados y de baja remuneración, pudiendo ganar más dinero en economías delictivas que además de doblar sus ingresos acompañan la búsqueda de respeto tan anhelada.

\section{"HACERSE EL MALO", OBTENER "RESPETO”}

La categoría "respeto", como ya dije, es muy utilizada en La Tela. En una oportunidad charlábamos sobre eso con Danilo, un joven de 28 años vecino de la villa. Él me contaba: 
"Yo andaba mucho en la calle, en el centro laburando de pendejo. Laburé limpiando vidrios, vendiendo estampitas en el bondi, tarjetas de navidad, pero todas esas cosas no me eran suficientes y empecé a robar. ${ }^{19}$ Cuando trabajas en la calle la gente te mira mucho y a mí me daba una bronca, te miran, te miran mal. Y después empecé a robar y caí en cana [lo metieron preso] y entonces cambié mucho la forma de ver las cosas, te va agarrando cada vez más bronca. Y bueno te tenés que hacer respetar, yo en la calle aprendí a hacerme respetar" [Danilo].

Danilo me explicaba cómo había sido su temprana inserción laboral y el comienzo de sus andanzas delictivas. Algo que me ha comentado en varias oportunidades es que otros trabajos más legales, como, por ejemplo, el de albañil, no son para él. Le pregunté por qué tenía esta apreciación y me respondió que a él no le gustaba recibir órdenes ni que lo "bolazeen". ${ }^{20}$ Danilo cayó preso en marzo de 2011 por robo, le otorgaron una condena de seis años, pero salió con libertad condicional en agosto de 2015. Sin embargo, en agosto de 2016 volvió a reincidir y fue apresado nuevamente. Este fragmento de entrevista pertenece a una conversación que tuvimos en noviembre de 2010. Ese día él estaba muy entusiasmado con la posibilidad de empezar a trabajar en una cooperativa en la villa que, con fondos de la Nación, se encargaría de realizar tareas de limpieza y construcción en La Tela. El fantaseaba con la idea de llegar a ser "jefe de la cooperativa". Las desventajas de una estructura social desigual llevan a muchos jóvenes, como Danilo, a sentir "bronca". Bronca hacia una sociedad que los "mira mal" cuando trabajan siendo niños, pero también si caen en una "economía clandestina". Bronca porque la estructura social termina beneficiando siempre a otros y perjudicándoles a ellos (Díaz Polanco 2006). Pero también frustración por no poseer los capitales necesarios para poder obtener otro tipo de empleos que conlleven menos esfuerzo físico, de mayor calificación y mejor valorados socialmente.

En estas circunstancias, volverse "peligroso" para los demás puede ser una estrategia seductora para canalizar la rabia e invertir, de alguna manera, la situación de dominación. Tomaré de Bourgois (2010) la categoría "cultura callejera de resistencia" para referirnos a lo que acabamos de describir: "Esa cultura callejera de resistencia no es un universo consciente o coherente de oposición política. Por el contrario, es un conjunto espontáneo de prácticas rebeldes que se ha forjado paulatinamente como un modo, un estilo de oposición" (Bourgois 2010: 38). Podríamos decir que Danilo utiliza a la violencia como estrategia de oposición a un entorno del cual siente que no forma parte o al menos, que la parte a la cual pertenece no es la parte más beneficiada de 
la estructura social. En relación con lo que he venido planteando voy a tomar aportes de Chaui (1998), quien critica aquellas perspectivas que se posicionan del lado de la ética y buscan generar un consenso sobre lo que se establece como mal. Al respecto, Chaui sostiene que:

"el sujeto ético o sujeto de derechos esta escindido en dos: de un lado un sujeto ético como víctima, como persona sufrida pasiva y de otro lado un sujeto ético piadoso y compasivo que identifica el sufrimiento [...] y que debe realizar justicia para los sin justicia" (1998: s/p.).

El problema se genera, para esta autora, cuando se produce "una inversión ideológica”, es decir, cuando ese sujeto pasivo digno de compasión decide abandonar su condición de víctima y reclamar otro lugar en la sociedad. Es en esas situaciones donde, lejos de ser considerado un sujeto, es concebido como un agente de violencia. En otras palabras, el sujeto ético de derechos necesita o bien de víctimas, o bien de personas violentas para constituirse como tal. La "cultura callejera de resistencia" podría ser una de las formas a través de las cuales las personas que viven en villas reclaman otros lugares en la sociedad, en ese proceso en el que abandonan el lugar de pobres personas que merecen recibir las obras caritativas de otros sectores sociales. Por el contrario, al adoptar actitudes consideradas violentas y al no aceptar las normas sociales, son juzgadas y señaladas como actores hacedores de violencias a los que se deben combatir y erradicar con políticas públicas de "mano dura". Por otra parte, Clark (1997) analiza cómo la compasión es imprescindible para sostener el orden social. Considera que esta emoción permite la conexión entre los "afortunados" y los "desafortunados". Permite que los últimos se vuelvan visibles para los primeros. La compasión es una manera de marcar límites entre "nosotros" y "los otros" y en este sentido posee una singular y asimétrica manera de conectar a quienes sienten compasión con quienes son compadecidos. En este sentido, se pregunta quiénes son los que pueden sentir compasión y quiénes no en un determinado contexto social y cómo entonces esto se convierte en una cuestión de jerarquía moral que se traduce en la esfera de la micropolítica. Este autor analiza con estas herramientas a la caridad como puesta en práctica, como acción que deviene de la compasión y cómo, a partir de ella, se va estableciendo el orden social y moral según las posiciones sociales que cada quién ocupa. Por eso sostiene que la compasión es una emoción asimétrica que se experimenta desde arriba hacia abajo. En otras palabras, que es legítima mientras es experimentada por personas que ocupan cierta posición social y que tienen cierta jerarquía moral. Mientras tanto, esto genera rabia, bronca y desprecio desde abajo, hacia arriba, es decir, por parte de quienes son ubicados en el lugar de compadecidos. La compasión genera reciprocidad, por lo que a veces la respuesta a ella es la bronca y la no aceptación del lugar de "compade- 
cidos". Sin embargo, esto se convierte en un círculo de reciprocidades "negativas" del que es muy difícil salirse. Porque este lugar de temidos los convierte en victimarios y como tales son merecedores del castigo social y otra vez del desprecio o, su opuesto, la compasión. En relación con esto, Bourgois (2010) analiza cómo la "cultura callejera de resistencia" termina convirtiéndose así en una alternativa autodestructiva.

Puede decirse que "hacerse el malo" es una manera de resistir un orden que se considera injusto, tanto dentro como fuera de la villa. Así, por ejemplo, muchos jóvenes utilizan la maldad como resistencia ante lo que consideran "faltas de respeto" respecto de otros vecinos, jefes, maestros, amigos y familiares. En este sentido, encuentro que los aportes de Ortner $(1995,2009)$ se vuelven una valiosa herramienta para reflexionar sobre cómo abordar la categoría de resistencia. La autora establece que hay que volver siempre a los casos etnográficos para pensar las múltiples maneras de resistir que tienen "los subordinados", quienes, a su vez, presentan heterogeneidades y ambivalencias en relación con sus trayectorias biográficas, sus posiciones sociales, géneros y grupos etarios.

\section{Quieren que les tengan miedo}

Una tarde soleada de septiembre de 2011 me recibieron en su casa Joaquín Manuel, de 29 años, y su novia Naty, de 31 . A ambos los conocí al inicio de mi trabajo de campo y siempre colaboraron animosamente conmigo. Me hicieron pasar al fondo de la casa, donde habitualmente me recibían los días de calor. Allí había un patio lleno de plantas y flores. Mientras Naty fue a poner la pava para tomar mate, Joaquín le pasaba un trapito a la mesa y a las sillas de plástico que estaban llenas de tierra. ${ }^{21}$ Conversamos de bueyes perdidos y poco a poco la charla se fue orientando hacia los vecinos que, como Danilo, robaban en la villa. La familia de Joaquín tenía una muy mala relación con Danilo y sus hermanos porque decía que eran unas "ratas", debido a que delinquían dentro de la villa. Robar en la villa es moralmente muy mal visto entre los vecinos; porque además de la ilegalidad que supone esa práctica, es doblemente condenada por el hecho de perjudicar a los propios vecinos, ya que "somos tan pobres como ellos y nos matamos laburando para conseguir las cosas" [Zuny, 50 años, madre de Joaquín]. A su vez, Joaquín me explicaba:

"Joaquín: Ellos [Danilo y sus hermanos] no roban por necesidad, roban porque son carteludos, para hacer cartel..$^{22} \mathrm{Y}$ por eso si caen en la cárcel

21 La pava es un recipiente para calentar agua. Se fabrica, generalmente, de aluminio u acero inoxidable.

22 "Hacer cartel" o ser un "carteludo" refiere a la persona que finge ser alguien que no es o que hace alarde de una supuesta cualidad que en realidad no se tiene. En este caso, refiere a que roban para aparentar ser "malos" y así ganar "respeto". Sin embargo, en estos casos la maldad no es una cualidad innata, si no fingida. 
cuando vuelven son los más carteludos de todos. Y vos ves que a ellos no les cuesta comprar las cosas, por eso se gastan la guita en joda, droga, bailes. Porque si vos trabajas y para darte un gusto vos lo pensas, pensas si te va a alcanzar después para comer, pero ellos no.

Naty: Como todo lo que tienen viene de arriba no tienen que hacer ningún esfuerzo para comprar las cosas.

Joaquín: Ellos creen que todo les tiene que venir de arriba, que tienen derecho a que vos les regales todo. Y se creen mejor que todos los que laburamos, así me dijo una vez en la cancha uno, que yo era un gil porque laburaba y ahí se armó y me tuve que cagar a piñas. ${ }^{23} \mathrm{Y}$ vos los ves que caminan así [imita una caminata como todo despilfarrado, con la pelvis hacia adelante y los brazos a los costados del cuerpo] y que se creen que se llevan todo por delante, pero si vos los enfrentas [pone actitud corporal como que se para delante de alguien] ahí nomás se van para atrás [imita a alguien que huye].

Naty y yo reímos.

Marina: ¿Y por qué será así?

Joaquín: Y porque tienen mucho resentimiento. Y la culpa no es de ellos sino de los padres que nunca les enseñaron nada. Ellos capaz lo veían al padre con unas zapatillas viejas que venía cansado de laburar y veían a otros del barrio con unas zapatillas Nike nuevas que se las habían choreado y cuando vos sos chico miras y aprendes de todo y acá se ve mucho el choreo y entonces, ¿qué va a elegir el pibe? Esos chicos tienen mucho resentimiento, tienen bronca de otros que tienen lo que ellos no pueden tener y entonces no les importa nada pegarte un tiro para robarte las zapatillas. Y nunca van a salir a laburar, ellos siempre quieren dominar, quieren ser jefes, no quieren tener patrón, quieren que les tengan miedo. Esos prefieren ser dueños de un peso que esclavos de dos" [Naty y Joaquín, febrero de 2011].

Joaquín hace un lúcido análisis de cómo ve él la situación de los que "chorean" en la villa. Explica que los jóvenes que roban no quieren trabajar porque ellos no desean tener un patrón que les de órdenes, sino que quieren dominar, tener autoridad, conseguir respeto. Analiza también cómo surge el resentimiento desde la infancia en los que deciden realizar actividades delictivas como una manera de obtener réditos económicos. Según Joaquín, estos jóvenes prefieren ser temidos por otras personas que someterse a las vicisitudes que, ya vimos, caracterizan al mundo laboral informal. Como veíamos anteriormente, a veces el trabajo que exige una intensa exposición corporal, como el de pocero o el de limpiavidrios muestra una presentación peligrosa de la propia persona a partir de la rudeza de un trabajo. Es decir que existe 
una inversión seductora de mostrarse como peligroso y demostrar fortaleza a partir de la realización de un trabajo determinado, como así también de llevar a cabo economías delictivas. Esto va de la mano con cierta estrategia seductora de ser temido para dominar a otros. Hay que tener en cuenta que Joaquín pertenece al contexto de La Tela, es parte de las relaciones sociales que tejen la vida social de la villa. Por tanto, está mirando, en palabras de Bourdieu (2007), desde un punto de vista que es una vista desde un punto. Es decir, desde un lugar de la estructura social, desde una trayectoria de vida, desde una trayectoria familiar, desde un acopio de conocimientos personales que ha ido tomando a lo largo de su vida. Joaquín viene de una familia que se mantuvo unida hasta bien entrada su juventud. Sus padres provienen de contextos rurales pobres y llegaron a la villa buscando las oportunidades que brinda la ciudad. En el año 2003, tras un tornado que azotó la zona sudoeste de la ciudad y destruyó gran cantidad de viviendas en La Tela, ambos consiguieron puestos de trabajo formales en la municipalidad de Córdoba, lo que les permitió abandonar la vieja economía de las "changas" y descansar sobre las seguridades de la dependencia laboral.

Respecto de la familia de Danilo, observamos que también se vio amenazada por las crisis económicas de fines de los 80. Sólo que, a diferencia de la de Joaquín, se disolvió tempranamente y eso modificó drásticamente la estructura familiar. Su madre quedó en la calle con ocho hijos que alimentar, dejando atrás un hogar signado por la violencia y el fracaso de un matrimonio. Míguez (2008) analiza cómo muchas veces la disolución de los vínculos familiares favorece la inserción de los jóvenes al mundo del delito. En este sentido, observa en estudios de caso que las familias monoparentales a veces carecen de una autoridad que establezca un orden en la experiencia cotidiana de los hijos. El autor reflexiona sobre cómo la temprana carencia material producida por una disociación entre las desigualdades en relación a la distribución social de los recursos y las exigencias y expectativas de la sociedad respecto del consumo predisponen a los jóvenes al delito. En esta línea, sigue a Merton quien encuentra una correlación entre "pobreza relativa" y "expectativas sociales" respecto de lo que nunca podrán tener, lo que genera mucho resentimiento. Joaquín lo explica claramente cuando nos dice que los vecinos "no roban por necesidad". En la entrevista, Joaquín afirma que sus vecinos roban para "hacer cartel", lo que está en parte relacionado con la necesidad de marcar cierta autoridad basada en la reputación. Es así como "choreando" se hacen la fama de "malos", necesaria para conseguir respeto, temor, mujeres, bienes materiales, prestigio, para destacar su masculinidad, entre otras cosas. Pero también así compensan la "bronca" que se siente al pertenecer a los últimos sectores sociales desde generaciones, la rabia producto de una sociedad de consumo que les marca exigencias sociales materiales y un estilo de vida a los que ellos no podrán acceder. 


\section{ALGUNAS CONCLUSIONES}

Trabajar con las categorías de miedo y peligro me fue de gran riqueza para ampliar y relativizar la mirada de cómo se estaba pensando la inseguridad en Argentina y concretamente en la ciudad de Córdoba, vinculada más a las clases medias y a las elites, desde donde se señalaba a las villas y barrios pobres como responsables de esa inseguridad. Entonces pensar en los diferentes sentidos sobre los miedos que se construían en La Tela me permitió acercarme a los diferentes discursos y prácticas que las propias personas de la villa configuraban respecto de esta problemática. Como todo grupo social, La Tela presentaba heterogeneidades que me permitieron ver cómo el miedo no estaba siempre relacionado con la inseguridad, sino también con otras variables como, por ejemplo, las desventajas estructurales de vivir en una villa, las acusaciones de otros sectores de la sociedad respecto de "causar inseguridad", las desigualdades en relación a otras clases sociales respecto de los capitales requeridos para conseguir empleos calificados en detrimento de aquellos de menor calificación que requieren mucho esfuerzo físico y, en ocasiones, humillaciones y malos tratos por parte de la patronal. Sin embargo, pude ver cómo, a su vez, este tipo de empleos servía para reafirmar la masculinidad y disputar "respeto" frente a otros pares.

Por otra parte, me fue posible observar cómo el miedo y el peligro tenían al menos una doble faceta entre quienes temían y quienes eran temidos, lo que, para algunas personas, principalmente jóvenes varones, se vislumbraba como una alternativa seductora para "invertir el miedo" y "hacerse el malo", volviéndose peligroso para otros. De esta manera, estos jóvenes se apropiaban de los estigmas otorgados desde afuera de la villa, pero también por los propios vecinos que los acusaban de reproducir los estereotipos que se construían desde otros sectores sociales. Puede analizar cómo, en ocasiones, el miedo causado a otros se transformaba en una forma de "resistencia" frente a un orden considerado injusto, tanto dentro como fuera de La Tela, aunque no de manera consciente. Atender a los casos etnográficos me permitió afinar la mirada para reflexionar sobre las diferentes resistencias que se traducían en La Tela en disputas y juegos de poder entre los vecinos de la villa. Las diferencias y distinciones nativas eran construidas respecto de sus trayectorias de vida y familiares, géneros, grupo etario, antigüedad en la villa y en contraste con la mirada que se configuraba "desde afuera" sobre la villa y sus habitantes. Estas diferencias daban lugar a construcciones ambiguas sobre el miedo en las cuales éste adquiría diferentes facetas.

Por último, respecto de mi propio lugar como etnógrafa en esa urdimbre de relaciones sociales, pude observar cómo en una primera instancia el miedo fue una manera de marcarme límites. De esta manera, al inicio de mi trabajo de campo yo misma fui advertida sobre los múltiples peligros a los que estaba expuesta por circular sola por determinados lugares de la villa, o relacionarme con cierto tipo de vecinos considerados, por otros, como "malos". Por ejemplo, 
por estar relacionados con actividades delictivas. Dichas advertencias fueron cesando a medida que fue pasando el tiempo, me fui relacionando con diferentes personas y me volví "de confianza". A partir de eso pude reflexionar acerca de cómo la confianza que se construye respecto de personas y lugares es inversa a las percepciones de miedo y de inseguridad, puesto que lo que es temido está más relacionado con lo desconocido.

\section{BIBLIOGRAFÍA}

BOURDieU, Pierre, 2007, La Miseria del Mundo. Buenos Aires. Fondo de Cultura Económica.

BOURGOIS, Philippe, 2010, En Busca de Respeto: Vendiendo Crack en Harlem. Buenos Aires, Siglo Veintiuno.

CHAUI, Marilena, 1998, "Ética e violência", Teoria e Debate, 39, disponible en < https:// teoriaedebate.org.br/1998/10/01/etica-e-violencia/ > (última consulta en diciembre de 2018).

CLARK, Candace, 1997, Misery and Company: Sympathy in Everyday Life. Chicago/Londres, University of Chicago Press.

DA SILVA CATELA, Ludmila, 2006, "Miedo al comunismo en Tumbaya”, en VVAA, Miedos y Memorias en las Sociedades Contemporáneas. Córdoba, Comunicarte Editorial, 81-97.

DíAZ POLANCO, Héctor, 2006, Elogio de la Diversidad: Globalización, Multiculturalismo y Etnofagia. Buenos Aires, Siglo XXI.

GARRIGA ZUCAL, José, 2007, Haciendo Amigos a las Piñas: Violencias y Redes Sociales de Una Hinchada de Fútbol. Buenos Aires, Prometeo.

GONZÁlez DE LA ROCHA, Mercedes, 2006, Procesos Domésticos y Vulnerabilidad: Perspectivas Antropológicas de los Hogares con Oportunidades. Méjico, DF, CIESAS.

GUBER, Rosana, 2004 [1984], "Identidad social villera”, en M. Boivin, A. Rosato y V. Arribas, Constructores de Otredad: Una Introducción a la Antropología Social y Cultural. Buenos Aires, Antropofagia, 115-125.

GUBER, Rosana, 2014, Prácticas Etnográficas: Ejercicios de Reflexividad de Antropólogas de Campo. Buenos Aires, IDES-Miño y Dávila.

HALBWACHS, Maurice, 2009 [1947], "A expressão das emoções e a sociedade", Revista Brasileira de Sociologia da Emoção, 8 (22): 201-218.

HALE, Chris, 1996, "Special issue on fear of crime: a review of the literature", International Review of Victimology, 4 (2): 79-150.

HATHAZY, Paul, 2014, "Inseguridades interpeladas: políticas contra el crimen y ciudadanías en la Córdoba neoliberal”, en N. Bermúdez y M.E. Previtali (comps.), Merodear la Ciudad: Miradas Antropológicas sobre Espacio Urbano e "Inseguridad" en Córdoba. Córdoba, Universidad Nacional de Córdoba, 27-55. 
ISLA, Alejandro, y Daniel MíGUEZ (comps.), 2003, Heridas Urbanas: Violencia Delictiva y Transformaciones Sociales en los Noventa. Buenos Aires, Editorial de las Ciencias.

KESSLER, Gabriel, 2007, "Miedo al crimen: representaciones colectivas, comportamientos individuales y acciones públicas”, en A. Isla (comp.), En los Márgenes de la Ley: Inseguridad y Violencia en el Cono Sur. Buenos Aires, Paidós, 69-99.

KESSLER, Gabriel, 2009, El Sentimiento de Inseguridad: Sociología del Temor al Delito. Buenos Aires. Siglo XXI.

KESSLER, Gabriel, 2013, "Ilegalismos en tres tiempos”, en R. Castel et al., Individuación, Precariedad, Inseguridad: ¿Desinstitucionalización del Presente? Buenos Aires, Paidós, 109$-165$.

LECHNER, Norbert, 1998, "Nuestros miedos", Perfiles Latinoamericanos, 7 (13): 179-198.

LIBERATORI, Marina, 2014, Y sí... Vivo en Una Villa: Una Etnografía sobre los Miedos y Peligros en Villa La Tela de Córdoba. Córdoba, Universidad Nacional de Córdoba, tesis de maestría en Antropología.

LiBerATORI, Marina, 2016, El Mal que Puede Volver: Antropología de los Sentidos sobre el Mal, Experiencias con Santos Populares y Relaciones Sociales en Villa La Tela (Córdoba). Córdoba, Universidad Nacional de Córdoba, tesis de doctorado en Ciencias Antropológicas.

LUPTON, Deborah, y John TULLOCH, 1999, "Theorizing fear of crime: beyond the rational/irrational opposition”, British Journal of Sociology, 50 (3): 507-523.

MíGueZ, Daniel, 2008, Delito y Cultura: Los Códigos de la Ilegalidad en la Juventud Marginal Urbana. Buenos Aires, Biblos.

MÍGUEZ, Daniel, y Alejandro ISLA, 2010, Entre la Inseguridad y el Temor: Instantáneas de la Sociedad Actual. Buenos Aires, Paidós.

ORTNER, Sherry B., 1995, "Resistance and the problem of ethnographic refusal", Comparative Studies in Society and History, 37 (1): 173-193.

ORTNER, Sherry B., 2009, "Resistencia densa: muerte y construcción cultural de agencia en el montañismo himalayo", Papeles de Trabajo: Revista electrónica del Instituto de Altos Estudios Sociales de la Universidad Nacional de General San Martin, 3 (5), disponible en < http:// www.unsam.edu.ar/ojs/index.php/papdetrab/issue/viewIssue/18/16> (última consulta en diciembre de 2018).

PAIN, Rachel, 2001, "Gender, age and fear in the city", Urban Studies, 38 (5-6): 899-913.

PUEX, Nathalie, 2003, "Las formas de la violencia en tiempos de crisis: una villa miseria en el conourbano bonaerense”, en A. Isla y D. Míguez (comps.), Heridas Urbanas: Violencia Delictiva y Transformaciones Sociales en los Noventa. Buenos Aires, Editorial de las Ciencias, 35-70.

RATIER, Hugo, 197 1, El Cabecita Negra. Buenos Aires, Centro Editor de América Latina.

REGUILLO, Rosana, 2006, "Los miedos: sus laberintos, sus monstruos, sus conjuros: una lectura socioantropológica”, Etnografías Contemporáneas, 2 (2): 45-72.

SVAMPA, Maristella, 2010, Civilización o Barbarie: De "Dispositivo de Legitimación" a "Gran Relato". Buenos Aires, Centro Haroldo Conti, Secretaría de Derechos Humanos.

VIANnA, Adriana, 2007, El Mal que Se Adivina: Policía y Minoridad en Río de Janeiro, 19101920. Buenos Aires, Departamento de publicaciones de la Universidad de Buenos Aires. 